\title{
Rainfall variability related to sea surface temperature anomalies in a Pacific-Andean basin into Ecuador and Peru
}

\author{
L. Pineda ${ }^{1,2}$, V. Ntegeka ${ }^{1, *}$, and P. Willems ${ }^{1}$ \\ ${ }^{1}$ KU Leuven, Department of Civil Engineering, Hydraulic section, 3001 Leuven, Belgium \\ ${ }^{2}$ Unidad de Ingeniería Civil, Geología y Minas, Universidad Técnica Particular de Loja, C/. Marcelino Champagnat S/N, \\ Loja, Ecuador \\ * currently at: Institute for Environment \& Sustainability (IES), European Commission-Joint Research Centre, TP261, Via \\ Enrico Fermi, 2749-I21027 Ispra (VA), Italy
}

Correspondence to: L. Pineda (luis.pineda@bwk.kuleuven.be)

Received: 18 May 2011 - Revised: 16 September 2011 - Accepted: 1 October 2012 - Published: 2 April 2013

\begin{abstract}
The spatiotemporal modes of seasonal rainfall variability and their relation with sea surface temperature anomalies (SSTA 1.2 indices) are examined in the transition from the coastal plain towards the western Andes cordillera in southern Ecuador/northwestern Peru using instrumental records (1970-2000) collected from the Catamayo-Chira basin. A multi-criteria data analysis is conducted within different elevation ranges. The criteria involve rotated principal components, cross correlations and temporal changes of anomalies in rainfall quantiles.

The results confirm that SSTA 1.2 indices influence rainfall variability over the coastal plain $(<510 \mathrm{~m}$ a.s.l. $)$ where forcing is dominant within December-May. The El Niño Southern Oscillation also plays a role inland of the coastal plain where a region of ENSO-like rainfall variability is found on the southeastern part of the basin $\left(4^{\circ} 30^{\prime}-\right.$ $5^{\circ} \mathrm{S} / 79^{\circ} 15^{\prime}-80^{\circ} \mathrm{W}$ ) within March-May (MAM). This suggests that inland distance and elevation are only partial controls of ocean-atmospheric forcing up to $\sim 1300 \mathrm{~m}$ a.s.l. Our analysis also provides evidence of the SSTA 1.2 indices influence in a large altitudinal range $\sim 1400-2700$ m a.s.l. confined to the southeastern basin. This region is found consistently perturbed by ENSO within MAM. We conclude that geo-morphological features of the southwestern Ecuadorian Andean ridges play a twofold role in the control of oceanatmospheric forcing. They can modulate the atmospheric circulation, leading to a dissipation of the signal, or they might favor meteorological processes, leading to enhancement of orographic precipitation. This would explain the observed ENSO signals in instrumental records at locations as high as $2700 \mathrm{~m}$ a.s.l.
\end{abstract}

\section{Introduction}

The relationship between heavy rainfall and anomalous tropical sea surface temperature (SST) on inter-annual scales is a well-known feature of coastal areas of southern Ecuador and northern Peru (SENP) (Horel and Cornejo Garrido, 1986; Goldberg et al., 1987; Tapley and Waylen, 1990; Takahashi, 2004 and Rossel and Cadier, 2009). Torrential rains and consequently high runoff and flooding are the result of strong positive sea surface temperature anomalies (SSTAs) along the coast of Peru and Ecuador and of an equatorward expansion of the Inter-Tropical Convergence Zone (ITCZ) over the eastern Pacific. On the other hand, a very strong and stable low level inversion traps moisture in the surface layer during cold phases (La Niña) of the El Niño Southern Oscillation phenomenon (ENSO) (Vuille et al., 2000).

Several investigations on the spatial extension of rainfall anomalies during ENSO events have been performed (Bendix and Bendix, 1998; Rossel et al., 1999; Bendix, 2000; Bendix et al., 2003). All studies showed that positive rainfall anomalies during ENSO mainly affect the coastal plain of Ecuador to the western slope of the Andes at altitudes $<1800 \mathrm{~m}$ a.s.l. (Bendix and Bendix, 2006). However, to date in SENP this boundary remains unclear, and much still has to be done to ascertain how far towards the Andes the signal is evident. Rossel and Cadier (2009) focused on the large-scale influence of ENSO on rainfall patterns over the coastal region, inter-Andean valleys and Amazon slope in Ecuador, and identified that the boundary of the positive ENSO influence corresponds with the relief of the Andes. Vuille et al. (2000) focused on the influence on the 
inter-Andean valleys ( $>2500 \mathrm{~m}$ a.s.1.). Although they have addressed the large-scale influence of ENSO, detailed basinwide assessments of the transition from the coastal plain towards the western Andean cordillera are still scarce in the literature. In SENP, ENSO influence on rainfall and floods in the Puyango-Tumbes basin was studied by Tarras-Wahlberg et al. (2006), who found that ENSO regulates rainfall patterns on large areas of this basin, but its significance diminishes inland of the coastal plain where topography plays a role in controlling regional patterns. Accordingly, further studies are needed to truly ascertain the role of ENSO on rainfall variability into Pacific-Andean basins.

This study focuses on the Catamayo-Chira basin, a Pacific-Andean system in SENP. This basin provides an important case of study because (i) the area is comparatively understudied, (ii) the catchment is well situated and covers a large altitudinal and climatic range (from $3700 \mathrm{~m}$ a.s.1. to sea level, and, from humid regions of the western Andean foothills to the semi-desert coastal plains). The region posses a rather special topography characterized by various small ridges and intersecting valleys in contrast to the two distinct mountain chains observed in the Ecuadorian and Peruvian Andes. These particular characteristics define extreme spatio-temporal rainfall variability. Like other Pacific-Andean systems, the lower part ( $<800 \mathrm{~m}$ a.s.1.) in the Catamayo-Chira basin experiences extreme precipitation during ENSO episodes (Tote et al., 2011).

The aim of this study is to clarify the spatiotemporal relationship between rainfall variability of a Pacific-Andean basin and SSTA 1.2 indices using instrumental rainfall records from the Catamayo-Chira in SENP for the 19702000 period. Specifically, this study attempts to shed new light on how geographical distance from the sea and elevation may control the influence of SSTA 1.2 indices on rainfall variability.

\section{Data and methods}

Northern South America is one of the domains with a conspicuous ENSO signal in precipitation (Rossel and Cadier, 2009). SSTAs in block $1.2\left(0-10^{\circ} \mathrm{S} / 80-90^{\circ} \mathrm{W}\right)$ have been found to perform as the best predictor for seasonal hydrological variables; see, e.g. Rossel and Cadier (2009) for monthly rainfall, and Gelati et al. (2010) for runoff in the central coast of Ecuador. Monthly SSTs in block 1.2 were obtained from the NOAA Climate Prediction Center, (http://www.cpc.ncep. noaa.gov/data/indices/).

Monthly precipitation was provided by the "Proyecto Catamayo-Chira", a bilateral project and Coordinator Water Authority between the Ecuadorian and Peruvian Meteorological and Hydrological Services (INAMHI and SENAMHI). The dataset consists of 42 monthly records whose quality was assured by Oñate et al. (2006) within the scope of the project Twinning European and Latin-American River
Basins for research (TWINLATIN). The records were homogenized for the 1970-2000 period by using double mass cumulative techniques and missing data were filled by linear regression among stations showing the highest inter-station cross correlations ( $>0.7$, always significant at 99\%) (Oñate et al., 2006). From the provided dataset a subset of 24 stations (Fig. 1) was sampled, verifying that (i) records were at least $90 \%$ complete in the period investigated to avoid introducing bias from infilled records and they embrace the extreme ENSO events $82 / 83$ and $97 / 98$, and (ii) they were equally distributed in the domain of the three studied elevation ranges.

Rainfall in the Catamayo-Chira basin shows a varying distribution in the transition from the Andean foothills towards coastal plains. The unimodal distribution observed for the highlands in the southwestern Ecuadorian Andes shifts from a rainy season starting in September-October towards a rainy season starting in December in the lower part; see Fig. 1. (left panel) (a) (Gonzanama, $2042 \mathrm{~m}$ a.s.1.), (b) (Paraje Grande, $555 \mathrm{~m}$ a.s.1.) and (c) (La Esperanza, $12 \mathrm{~m}$ a.s.1.). To capture modes of variability that can be associated to a dominant rainfall regimen in a given region, stations were grouped into three subsets on the basis of their elevation range and the observed monthly mean distribution. The groups are $<510$ (05), 511-1900 (10), > $1901 \mathrm{ma.s.1.} \mathrm{(09} \mathrm{stations)}$ (Fig. 1, center). To account for the noise in records associated with individual months and to capture patterns of variability within different seasons, 3-month sums were considered with the onset of the hydrological year set at September. The seasons are September-November (SON), December-February (DJF), March-May (MAM), June-August (JJA). Hence, the analysis was performed separately for each altitudinal range and for the 3-month periods.

In the first elevation range, rainfall fields exhibit similar patterns with well differentiated wet (DJF-MAM) and dry (SON-JJA) seasons. Here, the ENSO signal is evident as short duration/high intensity storms over the coastal plain up to $\sim 250 \mathrm{~m}$ a.s.1. within the wet season. In the middle and upper subsets, rainfall patterns are substantially different basinwide and the grouping in similar patterns is not straightforward. Above $510 \mathrm{~m}$ a.s.l., precipitation variability in the central and eastern basin is progressively influenced by orography and the topographical setting of the landscape. For instance, the records (> $1900 \mathrm{~m}$ a.s.1.) show a well-distributed, year-round precipitation. In those records the ENSO influence is less evident; it mostly appears as a persistent process leading to an enhancement of the wet season. Due to the noise added by the complex climatological influences driving precipitation occurrence, its signal becomes hidden and its detection more evasive.

Hereafter, we define ENSO events as those proposed by Rossel and Cadier (2009). When the sequence of at least three consecutive months where the monthly SST 1.2 index is above $23^{\circ} \mathrm{C}$ and exhibits a positive anomaly equal or greater to $1^{\circ} \mathrm{C}$, such events correspond with the periods May 1972-January 1973, June-September 1976, September 


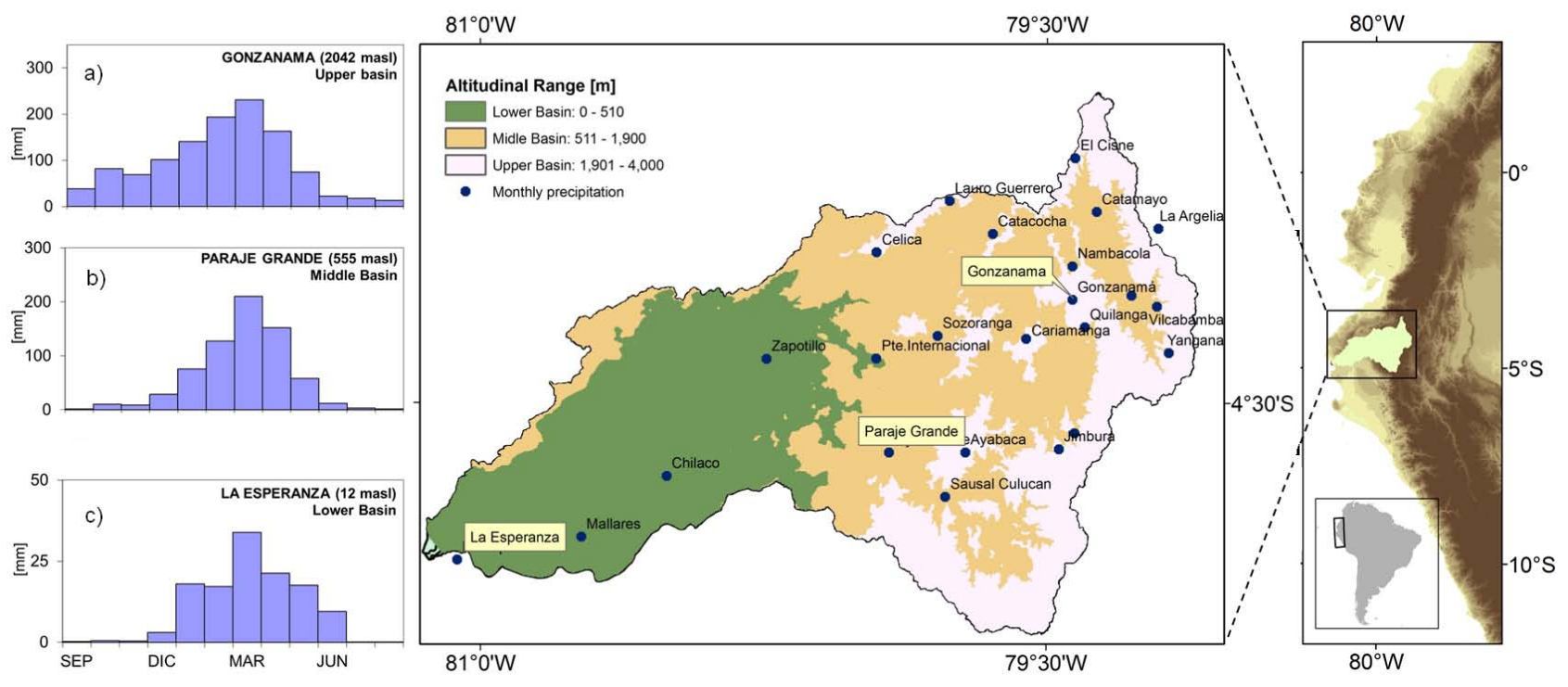

Fig. 1. (Left) Median monthly precipitation at (a) Gonzanama (2042 ma.s.1.), (b) Paraje Grande (555 ma.s.1.) and (c) La Esperanza (12 ma.s.1.). (Centre) Selected stations with monthly precipitation data in three different elevation ranges $(<510,511-1900$ and $>1901$ m a.s.1.) in the Catamayo-Chira basin. (Right) Catchment location in the Pacific-Andean watershed.

1982-September 1983, February-June 1987, March-May 1992 and April 1997-July 1998.

In this study, the first analysis criterion involves a principal component analysis (PCA) (Wilks, 2006) of seasonal rainfall and correlations of the resultant PCs factor scores series with seasonal (DJF-MAM-JJA-SON) SSTA 1.2 indices. The PCA was conducted in order to spot the dominant spatiotemporal modes of rainfall variability in each elevation range. The analysis was performed separately for each elevation range and for the 3-month periods - DJF, MAM, JJA, and SON based on the interstation correlation matrix of the precipitation data. To determine the number of principal components (PCs) that contain a nonrandom signal, the tests proposed by North et al. (1982) and Overland and Preisendorfer (1982) were applied. To quantify the degree of monotonic association between the identified patterns, the Kendall's tau $(\tau)$ correlation (Kendall, 1938) was computed and tested by significance between the resulting PCs time series (factor scores) and seasonal SSTA 1.2 indices. Next, the PCs retained were Varimax-rotated (VPCs) (Wilks, 2006) to allow further analysis of only the dominant modes. Their resultant VPCs loadings were plotted on station grid maps in order to spot stations/regions that might correspond with SSTA 1.2 indices influence at each elevation range.

The second approach was built on the basis of correlation analysis. To measure the sign and strength of linear association between seasonal (DJF, MAM, JJA, SON) station precipitation and time-lagged SSTA 1.2 indices, Pearson correlations $(r)$ were computed and tested by significance by applying the Student's t-test. As the seasonal station precipitation and time-lagged SSTA 1.2 indices exhibit vary- ing asymmetric distributions, variables were normalized by applying a log transformation. To account for the lag between oceanic forcing and continental precipitation response, the initial month of the corresponding season was considered (e.g. DJF precipitation was correlated with December SSTA 1.2 indices). Similar studies in the region, e.g. Vuille et al. (2000), have also assumed the initial month of the season as the time lag between both variables. To account for serial correlation that might lead to an erroneous statistical significance in the computation of correlations, the "effective" sample size (see Zwiers and von Storch, 1995) was considered in the t-test. Correlations $>0.4$, statistical significant at $5 \%$ level, were plotted on r-correlation plots and their coherency compared with the VPCs spatial loading maps derived from the first criterion.

To investigate in detail the spatiotemporal patterns detected with the former criteria, we analyze on a seasonal basis the middle and upper subsets that contain series suspected to be affected by ENSO non-stationarities, and also independent records (not included in the former analysis) with a statistical approach based on quantile anomalies. The approach is particular suitable for rainfall records where the ENSO signal is hidden by noise because it filters out information on the statistical frequency properties of the variable under study, which may lead to more clear teleconnection results (Ntegeka and Willems, 2008). The method allows investigation of temporal variability of the rainfall quantile anomalies by pre-selecting blocks of interest. In this study, 2-, 4and 8 -yr blocks were considered to relate rainfall anomalies with positive SSTA 1.2 indices, which in the examined period (1970-2000) show a varying cycle ranging $2-8$ yr. The 
Table 1. Summary statistics of the PCA (explained and cumulative variance) of seasonal precipitation (DJF, MAM, JJA, SON). Kendall's tau $(\tau)$ statistics for test of correlation between PC scores and seasonal SSTA 1.2 indices.

\begin{tabular}{|c|c|c|c|c|}
\hline \multirow[b]{2}{*}{$\begin{array}{l}\text { Principal } \\
\text { component }\end{array}$} & \multirow[b]{2}{*}{$\begin{array}{c}\text { Explained } \\
\text { variance }(\%)\end{array}$} & \multirow[b]{2}{*}{$\begin{array}{c}\text { Cumulative explained } \\
\text { variance }(\%)\end{array}$} & \multicolumn{2}{|c|}{ Kendall's tau statistics } \\
\hline & & & Correlation Coef. & $\mathrm{p}$-Value \\
\hline \multicolumn{5}{|c|}{$0-510 \mathrm{~m}$} \\
\hline DJF-PC1 & 81 & - & 0.20 & 0.052 \\
\hline MAM-PC1 & 83 & - & 0.53 & $1.7 \times 10^{-5}$ \\
\hline JJA-PC1 & 78 & - & 0.22 & 0.044 \\
\hline SON-PC1 & 56 & - & 0.11 & 0.180 \\
\hline \multicolumn{5}{|c|}{$511-1900 \mathrm{~m}$} \\
\hline DJF-PC2 & 15 & 72 & 0.13 & 0.150 \\
\hline MAM-PC1 & 47 & - & 0.39 & 0.001 \\
\hline JJA-PC2 & 16 & 57 & 0.21 & 0.050 \\
\hline SON-PC1 & 52 & - & 0.17 & 0.100 \\
\hline \multicolumn{5}{|c|}{$1901-4000 \mathrm{~m}$} \\
\hline DJF-PC2 & 12 & 70 & 0.14 & 0.130 \\
\hline MAM-PC1 & 59 & - & 0.30 & 0.009 \\
\hline JJA-PC1 & 48 & - & 0.20 & 0.107 \\
\hline SON-PC1 & 55 & - & 0.06 & 0.060 \\
\hline
\end{tabular}

Numbers in bold are considered statistically significant $(p \leq 0.05)$.

approach involves sampling on seasonal basis (DJF-MAMJJA-SON) empirical quantiles within different moving sliding blocks (2-, 4-, 8-yr), followed by calculation of the quantile anomalies (also called perturbation factors) as the ratio between the quantiles in the sliding blocks over the same quantiles based on the full available period (1970-2000). These perturbations represent the changes with respect to the long-term historical data. Then, the mean quantile anomaly (a single perturbation factor per block) is computed as the average of all perturbation factors above a particular threshold, which for this study is taken as 0.1 exceedance probability. This means that the single perturbation can be seen as a quantile perturbation for extreme rainfall conditions.

The single perturbation factor represents the anomalies in quantiles and is centered on each block and then plotted on annual basis to evaluate its temporal evolution. The result of the perturbation analysis is a percentage change of seasonal rainfall quantiles. The seasonal long-term climatological reference is zero and represents the expected rainfall for the studied year-block. Hence, the method allows detection of inter-annual oscillations in extreme quantiles; for a comprehensive and a more detailed description of the methodology see Ntegeka and Willems (2008) and Mora and Willems (2011).

The moving window procedure causes dependency among the calculated anomalies (over the studied periods) but allows easier visual interpretation of the temporal variations in these anomalies. To quantify the degree of association between the seasonal quantile anomalies and seasonal (DJF, MAM, JJA, SON) SSTA 1.2 indices, again Kendall's tau $(\tau)$ correlations (Kendall, 1938) were computed and tested by statistical significance.

\section{Results}

The seasonal PCA and the Kendall's tau $(\tau)$ correlation test statistics are summarized in Table 1. The station grid maps of VPCs loadings, together with the Pearson r-correlation plots of seasonal precipitation and one-month lagged SSTA 1.2 indices, are presented in Figs. 2 and 3. The normalized PCs factor scores series, jointly with seasonal SSTA 1.2 indices, are shown in Fig. 4. The Kendall's tau $(\tau)$ correlation test statistics for the association between the precipitation quantile anomaly and SSTA 1.2 indices (in four stations) are summarized in Table 2. Only the seasonal PCs that show coherent spatiotemporal patterns after the multi-criteria check are discussed on a seasonal basis for each elevation range.

\subsection{Lower basin}

DJF and MAM emerge as the seasons with clear ENSO signal in rainfall. Their PC1s explain 81 and $83 \%$ of the rainfall variability (Table 1 ) and $\tau=0.22$ and 0.53 , respectively. Particularly interesting is MAM PC1 score because of the close matching with SSTA 1.2 indices (Fig. 4b). This suggests a quasi-synchronized anomalous rainfall response to oceanic 

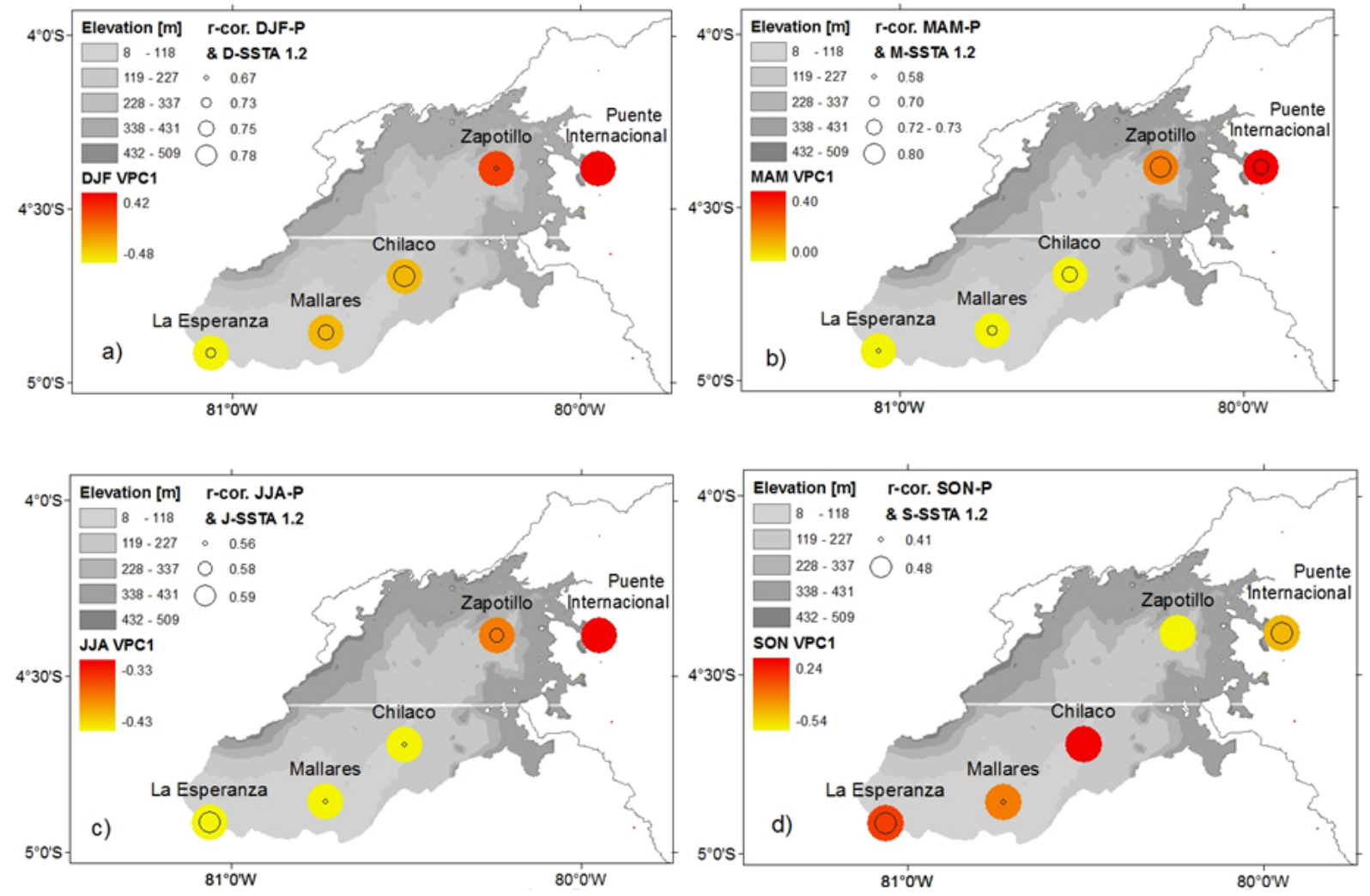

Fig. 2. Loading pattern of seasonal VPC (graded color: red-yellow), and, r-correlation plot of seasonal precipitation with one-month lagged SSTA 1.2 (graded dots) in the lower basin, for (a) VPC1 in DJF, (b) VPC1 in MAM, (c) VPC1 in JJA and (d) VPC1 in SON.

forcing in MAM. This response is consistent in magnitude and timing in all ENSO events. The strong ENSO signal in MAM can be partially explained by the fact that SSTA 1.2 indices often peak around MAM and the wet season reach its peak in March as well. In DJF the matching in timing and magnitude is restricted to the strongest ENSO events (97/98, 82/83 and 72/73) (Fig. 4a). On the other hand, in Fig. 2a, b, the r-correlation plots show a larger spatial influence of SSTA 1.2 indices in MAM than in DJF. In the same figure panels the Varimax-rotated DJF VPC1 and MAM VPC1 differentiate two zones, with the high loadings found on the upper stations. These two zones correspond with (i) the discrete, intense and localized storms prevailing in the arid low lands, and (ii) the larger rainfall spatial distribution observed on the slopes of the Andes ridges (upper stations in the lower basin). The mechanism generating such differences in convective systems has been identified as the sea breeze (Horel and Cornejo-Garrido, 1986; Goldberg et al., 1987; Bendix and Bendix, 1998; Takahashi, 2004) in the neighbouring Piura basin, which is a local circulation driven by the differential heating of the land and sea by the Sun. In the Piura region (which embraces the lower part of the Catamayo-Chira basin), onshore flow may force air over the slopes of the mountains, which are approximately $130 \mathrm{~km}$ inland, and the associated lifting may trigger convection (Takahashi et al.,
2004). This mechanism could explain the two varying spatial patterns depicted by both DJF VPC1 and MAM VPC1 in Fig. 2a, b.

In JJA the PC1 explains $78 \%$ of the rainfall variability ( $\tau=0.22$, at $5 \%$ statistical significance level). The JJA PC1 score (not shown) describes a synchronized rainfall anomaly in ENSO-82/83 and a less evident one in ENSO-97/98. Since JJA represents transition to the dry season, precipitation can still be substantial in June, especially in ENSO years. In Fig. 2c the r-correlation plot portrays a homogenous weak SSTA 1.2 indices spatial influence. The JJA VPC1 loadings define the same zones described for DJF and MAM. This denotes the marked differences between rainfall regimes between the upper/lower stations. However, on the whole the ENSO signal appears diminished.

In SON, two PCs emerge as containing nonrandom information. The temporal evolution of SON PC1 score (not shown) denotes an ENSO-like influence, but $\tau$ is the lowest in the region and not statistically significant at $5 \%$ level (Table 1). After rotation of the SON VPC1, the same two groups are revealed (Fig. 2d) but the spatial coherency in the r-correlations plot is poor. We conclude that in the lower basin the differences in rainfall regimen (upper/lower stations) are evident in all seasons, and the ENSO influence is 

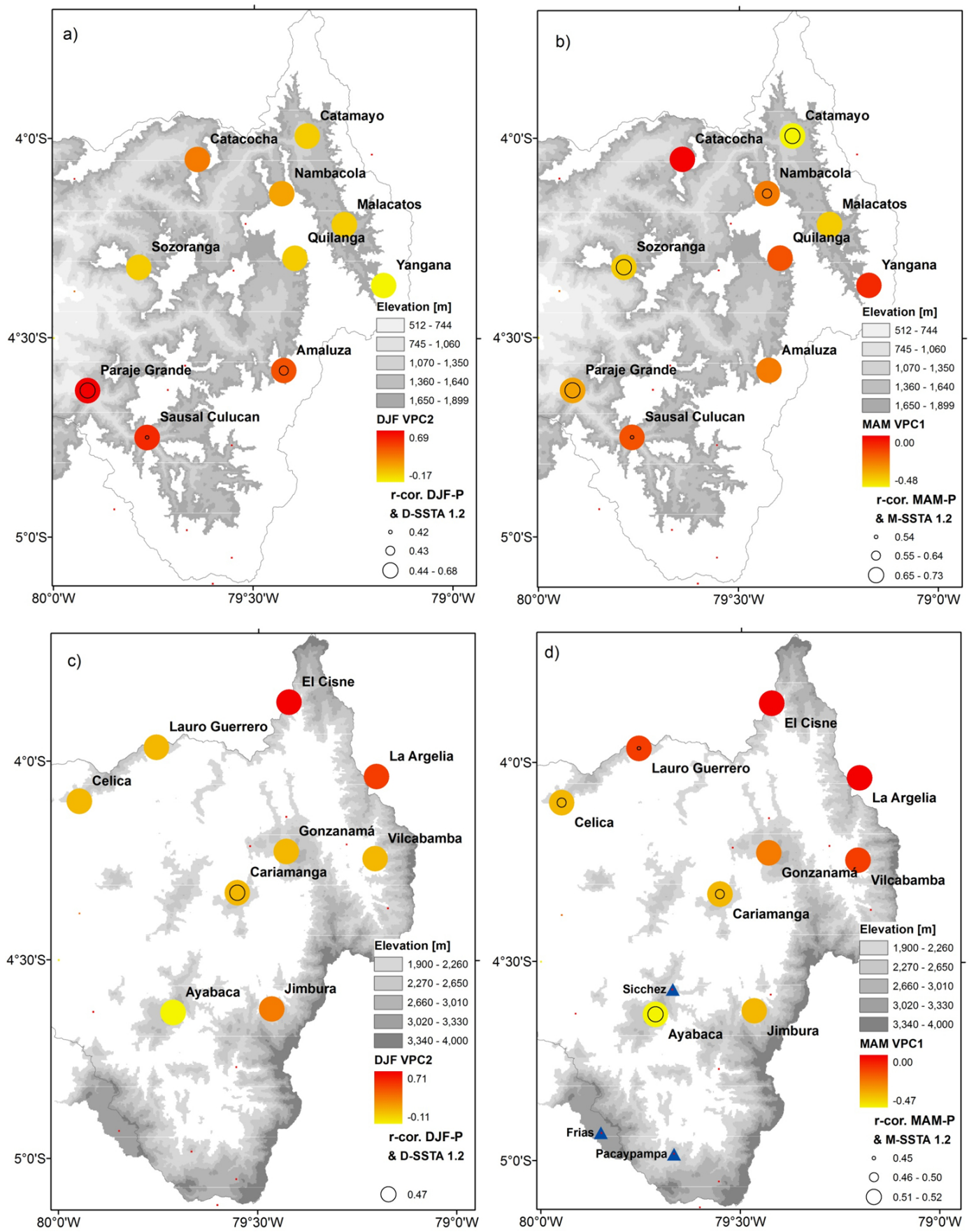

Fig. 3. Loading pattern of seasonal VPC (graded color: red-yellow), and, r-correlation plot of seasonal precipitation with one-month lagged SSTA 1.2 (graded dots) for (a) VPC2 in DJF and middle basin, (b) VPC1 in MAM and middle basin, (c) VPC2 in DJF and upper basin and (d) VPC1 in MAM and upper basin, and, location of stations: Frias, Sicchez and Pacaypamba in the upper basin.

strong in DJF-MAM, weak in JJA and near insignificant in SON.

\subsection{Middle basin}

In DJF, two modes explain $72 \%$ of the rainfall variability. None of them yields $\tau$ statistically significant at the $5 \%$.
In Fig. 3a, the DJF VPC2 loadings and the r-correlation plot (Fig. 3a) define two regions: (i) the southeastern part of the basin $\left(4^{\circ} 30^{\prime}-5^{\circ} 0^{\prime} \mathrm{S} / 79^{\circ} 30^{\prime}-80^{\circ} 0^{\prime} \mathrm{W}\right)$ with consistent $\mathrm{r}$-correlation, and (ii) the northeastern region (low loadings) where no significant correlations are found in the $\mathrm{r}$ correlation plot. This suggests a preferential path of SSTA 

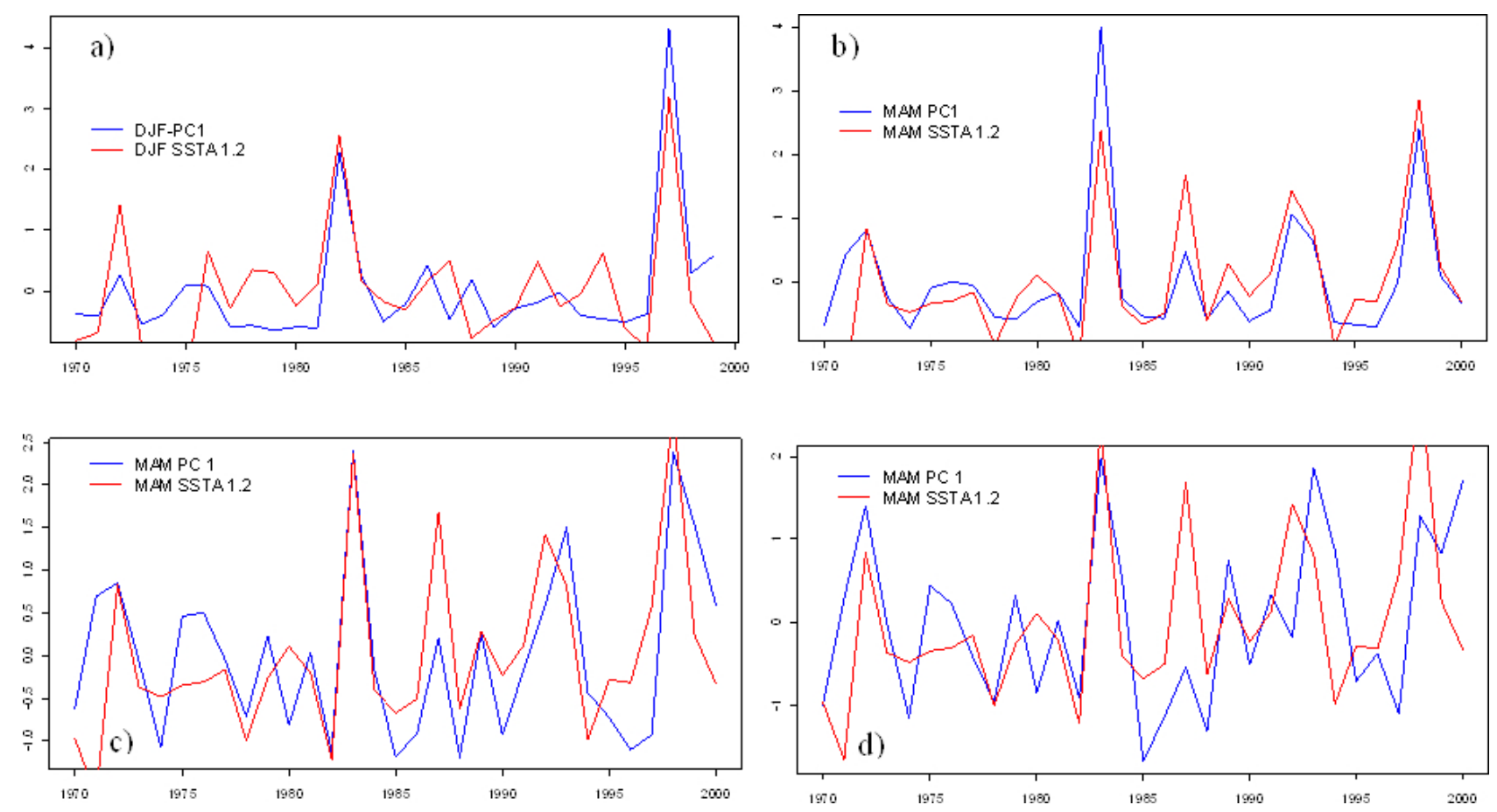

Fig. 4. (a) Normalized score time series of PC1 and seasonal SSTA 1.2, for (a) DJF and lower basin, (b) MAM and lower basin, (c) MAM and middle basin and (d) MAM and upper basin.

Table 2. Kendall's tau statistics for the test of association between 2-yr MAM precipitation quantile anomalies and MAM SSTA 1.2 indices. Numbers in bold are considered statistically significant $(p \leq 0.05)$.

\begin{tabular}{lccc}
\hline Stations & Elevation $[\mathrm{m}]$ & \multicolumn{2}{c}{ Kendall's tau statistics } \\
\cline { 3 - 4 } & & Correlation Coef. & p-Value \\
\hline Ayabaca & 2700 & 0.22 & $\mathbf{0 . 0 5 2 0}$ \\
Pacaypamba & 1960 & 0.31 & $\mathbf{0 . 0 3 2 0}$ \\
Frias & 1700 & 0.40 & $\mathbf{0 . 0 0 5 0}$ \\
Sicchez & 1400 & 0.24 & 0.0700 \\
\hline
\end{tabular}

1.2 indices influence that follows the southeastern Andes escarpments.

MAM reveals the strongest ENSO signal in the middle basin. The PC1 captures $47 \%$ of the variance and $\tau=0.39$ (statistically significant at $5 \%$ level) is the highest among all seasons. The MAM PC1 score shows positive rainfall anomalies to correspond with SSTA 1.2 indices in all ENSO events (Fig. 4c). In Fig. 3b the MAM VPC1 loadings are scattered basin-wide. The same holds in the r-correlation plot, making it difficult to discriminate clusters except for in the southeastern basin. This recurrent intra-seasonal pattern observed in the south-central basin (Paraje Grande, $555 \mathrm{~m}$ a.s.1. and Sausal de Culucan, $980 \mathrm{~m}$ a.s.l.) is connected to that observed by Goldberg et al. (1987), $400 \mathrm{~km}$ south in the neighboring basin of Piura. They found for ENSO 82/83 that the nearby region of Chulucanas $\left(5.10^{\circ} \mathrm{S}-80.17^{\circ} \mathrm{W}, 95 \mathrm{~m}\right.$ a.s.1. $)$ appeared to be a focal point for the initiation of localized storms of high intensity which then disperse over wider areas in the region. The region proposed by Goldberg et al. (1987) seems to include the south-central CatamayoChira $\left(4^{\circ} 30^{\prime}-5^{\circ} 0^{\prime} \mathrm{S} / 79^{\circ} 30^{\prime}-80^{\circ} 0^{\prime} \mathrm{W}\right)$. Further Fig. 3b suggests a wider spatial SSTA 1.2 indices influence below $\sim 1300 \mathrm{~m}$ a.s.l. following the relief of the northeastern Andean ridges and reaching the inner-most valleys (i.e. Catamayo, $\sim 1250 \mathrm{~m}$ a.s.1.). Such valleys are in proximity to the "Nudo de Loja", which is described by Rollenbeck et al. (2011) as a zone of extreme rainfall variability due to the convergence and mixture of climatological influences (Pacific and Amazonic), and considered to be both part of the great continental divide and the gateway that channels air masses crossing the Andes. This would explain the progressive altitudinal dissipation of the ENSO signal, even in its peak season (MAM), which is observed in the Catamayo region at $1250 \mathrm{~m}$ a.s.l. but not at higher altitudes (Fig. 3d).

In JJA a weak SSTA 1.2 indices influence could be found in the PC2, which explains $16 \%$ of the total variance ( $\tau=$ 0.21 , at $5 \%$ statistial significance level). The JJA VPC2 loadings look scattered in the studied domain. High values coincide with the r-correlation plot (not shown) only in the southcentral basin (Paraje Grande, $555 \mathrm{~m}$ a.s.l.). So it might be argued that, analogous to what is observed in the lower basin, the ENSO intra-seasonal influence prevailing in MAM seems to extend dimly to JJA. 

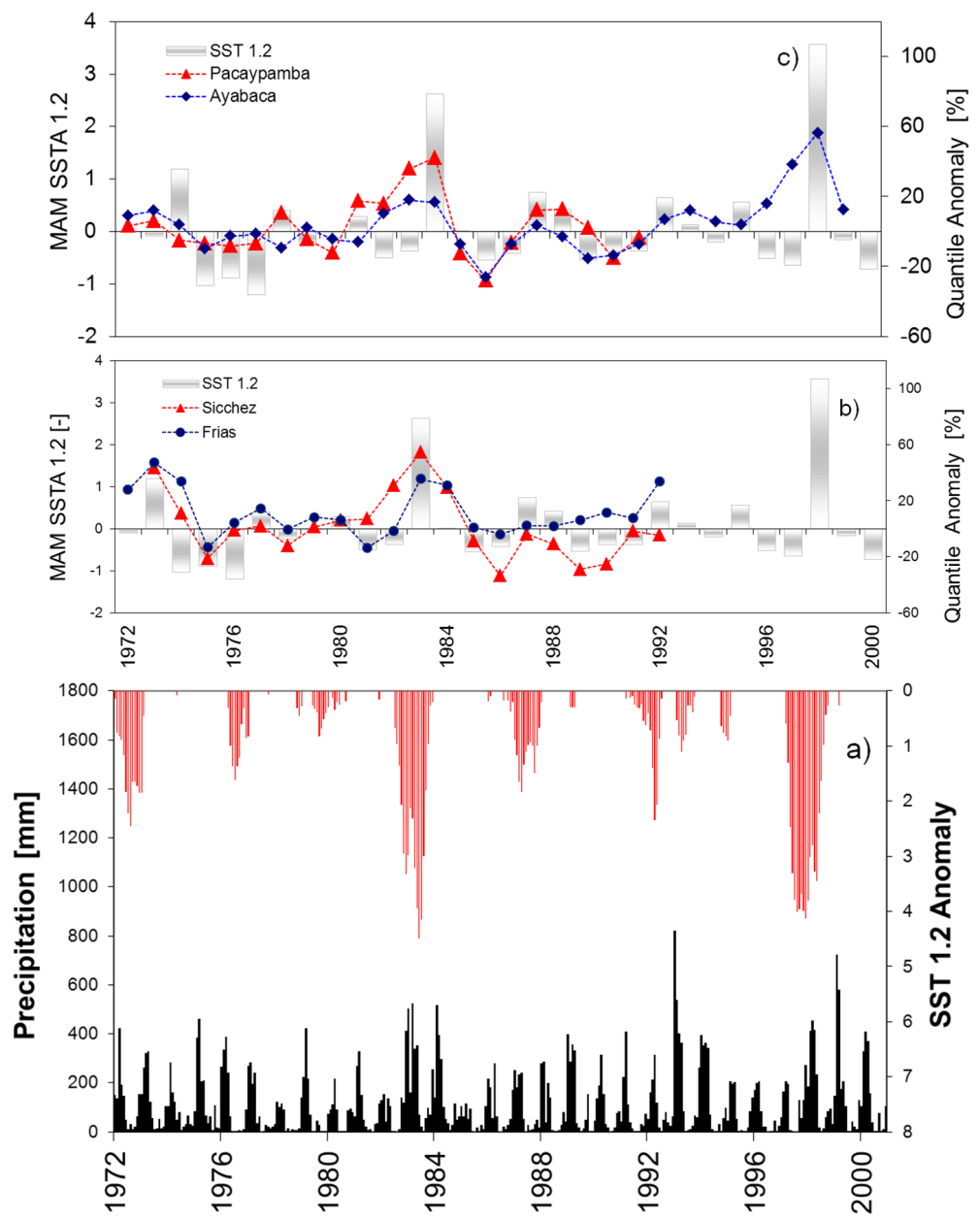

Fig. 5. (a) Series of monthly precipitation at Ayabaca $(2700 \mathrm{~m})$ and positive SSTA 1.2. (b) MAM precipitation quantile anomaly for a 2-yr block at Sicchez $(1400 \mathrm{~m})$ and Frias $(1700 \mathrm{~m})$. (c) Same as before but for Pacaypamba (1960 m) and Ayabaca (2700 m).

In SON the PC1 explain a substantial $52 \%$ of the rainfall variability, whereas $\tau$ is not significant at $5 \%$ level. The SON VPC1 loadings are dispersed, resembling those observed in JJA. However, neither comparison with r-correlation plots (not shown) nor inspection of the temporal evolution of the SON-PC1 score series suggests SSTA 1.2 indices influence.

\subsection{Upper basin}

Two PCs explain $70 \%$ of the rainfall variability in DJF. The PC2 explains $12 \%$ of the total variance, but, $\tau$ is not significant at $5 \%$ level. The temporal evolution of DJF PC2 score (not shown) does not provide links between oceanic forcing and anomalous precipitation. In Fig. $3 c$ the DJF VPC2 loadings show a north-south gradient that illustrates the regional differences in DJF precipitation, which is wetter in the northern basin. The r-correlation confirms the nearly inexistent ENSO influence.

In MAM the inspection of the MAM PC1 score series (Fig. 4d), which explains $59 \%$ of the rainfall variability
( $\tau=0.30$, at the $5 \%$ level), suggests still an ENSO-like pattern. The same north-south precipitation gradient is defined by MAM VPC1 loadings (Fig. 3d). The r-correlation plot defines a focus of influence on Ayabaca ( $\sim 2700$ m a.s.l.) linked with that described in the middle southeastern basin. This recurrent pattern was assessed in the surroundings of Ayabaca (Pacaypamba, Sicchez and Frias; see locations in Fig. 3d) by using the quantile perturbation approach. In this region, rainfall records show persistent processes during ENSO episodes leading to wetter years with an earlier onset and a later diminish of the wet season; see, e.g. Fig. 5a, which shows the persistence (non-stationarities) induced in the monthly precipitation in Ayabaca $(\sim 2700 \mathrm{~m})$ during positive SSTA 1.2 indices. The analysis of the temporal evolution of quantile anomalies is presented in Fig. 5b for Sicchez (1400) and Frias (1700), and in Fig. 5c for Pacaypamba (1960) and Ayabaca (2700 m a.s.1.). They reveal the ENSO influence on the 2-yr rainfall variability for the MAM season. Figure $5 b$ and $\mathrm{c}$ illustrate how, in a large altitudinal range confined to the southeastern basin, the departures of the seasonal rainfall 
quantiles from the 30-yr climatological reference (anomalies) are associated with their paired seasonal SSTA 1.2 indices during MAM when a 2-yr period is considered. Similar results (not shown) were obtained for the 4- and 8$\mathrm{yr}$ analysis, depicting the same degree of association. The Kendall's tau statistics for the 2-yr analysis (Table 2) support the strength of such a relation.

In JJA, the leading PC1 explains $48 \%$ of the variability but $\tau$ is not statistical significant at $5 \%$ level. The JJA VPC1 yields loadings scattered basin-wide. None of the remaining criteria provided evidence of SSTA 1.2 indices influence within this season.

In SON, the PC1 explains a substantial $55 \%$ of the total variance and $\tau=0.30$ ( $\mathrm{p}$-Value $=0.06)$, almost reaching statistical significance level. Its SON PC1 score (not shown) depicts a weak consistence with ENSO only in the 82/83 and $97 / 98$ events. In the r-correlation plot, some spots that suggest oceanic forcing are found again in Ayabaca and to a lesser degree over the central and northern Andean ridges (not shown). This is explained by the north-south precipitation gradient, which shows that southern stations better resemble the SSTA 1.2 indices cycle. However, on the whole the ENSO influence is found to be rather weak.

\section{Summary and conclusions}

Detection of the influence of SSTA 1.2 indices in instrumental records over the western Andean-Pacific basin is not trivial from the physical as well as from the data analysis point of view. Through a multi-criteria data analysis, we investigated the main seasonal spatiotemporal modes of rainfall variability in the Catamayo-Chira basin. As a result, several regions and seasons of ENSO influence emerged.

In the lower basin $\left(4^{\circ} 15^{\prime}-5^{\circ} \mathrm{S} / 80-81^{\circ} \mathrm{W}\right)$, the ENSO signal is consistently found in the rainfall records within the wet season DJF-MAM up to $\sim 500 \mathrm{~m}$ a.s.l. The period MAM shows the strongest monotonic association with SSTA 1.2 indices within 1970-2000. For the dry season the influence is weak in JJA and nearly insignificant in SON; only the exceptional anomalies 82/83 and 97/98 in JJA and 82/83 in SON could be associated with anomalous rainfall. The pattern observed within MAM suggests a link between continental meteorological response and near ocean-atmosphere dynamics operating entirely during the examined timespan. For the differences in the spatial influence of ENSO, in the lower basin, a mechanism linked with a local circulation (sea breeze) and its interaction with the gentle mountain slopes is argued to create the conditions for the observed phenomena.

One of the most significant results of this study came out in the transition from the lower basin $(\sim 510$ m a.s.l.) towards the humid Andean foothills, where two patterns of variability associated with SSTA 1.2 indices were found. In the northeastern part of the basin $\left(4-4^{\circ} 30^{\prime} \mathrm{S} / 79^{\circ} 15^{\prime}-80^{\circ} \mathrm{W}\right)$, it is observed that SSTA 1.2 indices, depending on their magnitude, can reach the innermost valleys $(\sim 1300$ ma.s.l.) following the Andean ridges relief, but they gradually dissipate with elevation, landscape setting and its interaction with other climatological processes. Conversely, in the southeastern basin $\left(4^{\circ} 30^{\prime}-5^{\circ} \mathrm{S} / 79^{\circ} 15^{\prime}-80^{\circ} \mathrm{W}\right)$ a region of homogeneous variability linked with SSTA 1.2 indices was found in a large altitudinal range ( $\sim 555-2700 \mathrm{~m}$ a.s.l.). The latter is in line with what was observed by Goldberg et al. (1987) for the ENSO event 82/83 anomaly; however, our analyses add evidence of oceanic forcing within other anomalous episodes during the examined period.

While the complex geo-morphological features of the western Andes ridges pose a challenge to ascertain the influence of the ocean-atmospheric forcing in the Andean-Pacific watershed of southern Ecuador/northern Peru. We provide some proof that elevation of the western Andes cordillera and the shape of its branches might have an imposing effect on this influence at hydrological unit scale. The naturally shaped valleys can act as channels capturing moisture and enhancing the complex dynamics of orographic precipitation or they can modulate and dissipate the atmospheric circulation during episodes of SSTAs. Physical based research is required to understand the complex mechanisms operating behind these phenomena.

Acknowledgements. The first author gratefully acknowledges the financial support of the EMECW Program of the European Commission in KU Leuven. Part of this study was conducted while L. Pineda was enrolled at ETH Zurich in the Postgraduate Programme Advanced Master in Sustainable Water Resources in the Group of Hydrology and Water Resources Management. The first author is also grateful to Paolo Burlando for providing him with appropriate conditions to do research during his stay in Zurich. Special thanks are due to P. Molnar and one anonymous reviewer whose comments led to the improvement of the different stages of this work.

\section{References}

Bendix, J.: Precipitation dynamics in Ecuador and Northern Peru during the 1991/92 El Niño - A Remote Sensing perspective, Int. J. Remote Sens., 21, 533-548, 2000.

Bendix, J. and Bendix, A.: Climatological Aspects of the 1991/92 El Niño in Ecuador, Bulletin de L'Institut Francaise d'Etudes Andines, 27, 655-666, 1998.

Bendix, A. and Bendix, J.: Heavy rainfall episodes in Ecuador during El Niño events and associated regional atmospheric circulation and SST patterns, Adv. Geosci., 6, 43-49, doi:10.5194/adgeo-6-43-2006, 2006.

Bendix, J., Gämmerler, S., Reudenbach, C., and Bendix, A.: A case study on rainfall formation during El Niño 1997/98 in Ecuador and surrounding areas as inferred from GOES-8 and TRMM-PR observations, Erdkunde, 57, 81-93, 2003.

Gelati, E., Madsen, H., and Rosbjerg, D.: Markov-switching model for nonstationary runoff conditioned on El Niño information, 
Water Resour. Res., 46, W02517, doi:10.1029/2009WR007736, 2010.

Goldberg, R., Tisnado, G. M., and Scofield, R. A.: Characteristics of extreme rainfall events in northwestern Peru during the 1982-1983 El Niño period, J. Geophys. Res., 92, 14225-14241, doi:10.1029/JC092iC13p14225, 1987.

Horel, J. D. and Cornejo Garrido, A. G.: Convection along the coast of Northern Peru during 1983 - Spatial and temporal variation of clouds and rainfall, Mon. Weather Rev., 114, 2091-2105, 1986.

Kendall, M.: A New Measure of Rank Correlation, Biometrika, 30, 81-93, doi:10.1093/biomet/30.1-2.81, 1938.

Mora, D. and Willems, P.: Decadal oscillations in rainfall and air temperature in the Paute River Basin-Southern Andes of Ecuador, Theor. Appl. Climatol., 108, 267-282, doi:10.1007/s00704-011-0527-4, 2011.

North, G. R., Bell, T. L., Cahalan, R. F., and Moeng, F. J.: Sampling errors in the estimation of empirical orthogonal function, Mon. Weather Rev., 110, 699-706, 1982.

Ntegeka, V. and Willems, P.: Trends and multidecadal oscillations in rainfall extremes, based on a more than 100-year time series of 10 min rainfall intensities at Uccle, Belgium, Water Resour. Res., 44, W07402, doi:10.1029/2007WR006471, 2008.

Oñate, F., Duque, E., Leon, P., Duque, F., Rojas, W., and Tenesaca, F.: Caracterización climática, metereológica y hidrológica de la cuenca binacional Catamayo-Chira previo a la implementación de los modelos SWAT y WATEM/SEDEM con fines de su planificación territorial, available at: http://www.fronate.pro.ec/fronate/wp-content/media/2008/ 01/caracterizacion-climatica-catamayo-chira.pdf, 2006.

Overland, J. E. and Preisendorfer, R. W.: A significance test for principal component analysis applied to a cyclone climatology, Mon. Weather Rev., 110, 1-4, 1982.
Rollenbeck, R., Bendix, J., and Fabian, P.: Spatial and temporal dynamics of atmospheric water inputs in tropical mountain forests of South Ecuador, Hydrol. Process., 25, 344-352, doi:10.1002/hyp.7799, 2011.

Rossel, F. and Cadier, E.: El Niño and prediction of anomalous monthly rainfall in Ecuador, Hydrol. Process., 23, 3253-3260, doi:10.1002/hyp.7401, 2009.

Rossel, F., Le Goulven, P., and Cadier, E.: Areal distribution of the influence of ENSO on the annual rainfall in Ecuador, Revue de Sciences de l'Eau, 132, 183-200, 1999.

Takahashi, K.: The atmospheric circulation associated with extreme rainfall events in Piura, Peru, during the 1997-1998 and 2002 El Niño events, Ann. Geophys., 22, 3917-3926, doi:10.5194/angeo22-3917-2004, 2004.

Tapley, T. D. and Waylen, P. R.: Spatial variability of annual precipitation and ENSO events in western Peru, Hydrolog. Sci. J., 8, 429-446, 1990.

Tarras-Wahlberg, N., Cauwell., S., and Lane, S.: El Niño events, rainfall patterns and floods in the Puyango River Basin, Southern Ecuador, Revista Brasileira de Metereologia, 21, 201-210, 2006.

Tote, C., Govers, G., Van Kerckhoven, S., Filiberto, I., Verstraeten, G., and Eerens, H: Effect of ENSO events on sediment production in a large coastal basin in northern Peru, Earth Surf. Process. Landforms, 36, 1776-1788, doi:10.1002/esp.2200, 2011.

Vuille, M., Raymond, S. B., and Keimig, F.: Climate Variability in the Andes of Ecuador and its relation to tropical Pacific and Atlantic Sea Surface Temperature anomalies, J. Climate, 13, 2520 2535, 2000.

Wilks, D. S.: Statistical Methods in the Atmospheric Sciences, 2nd Edn., Elsevier, 467-507, 2006.

Zwiers, F. W. and von Storch, H.: Taking serial correlation into account in test of the mean, J. Climate, 8, 336-351, 1995. 